Paidéia, 2004, 14 (28), 191-195

\title{
PANORAMA DA PSICOLOGIA ESCOLAR NA CIDADE DE VITÓRIA: UM ESTUDO EXPLORATÓRIO ${ }^{1}$
}

\author{
Claudia Broetto Rossetti ${ }^{2}$ \\ Carolina Alves Silva \\ Giuliano Loureiro Batista \\ Leila Alves Stein \\ Luciana de Oliveira Hulle \\ Universidade Federal do Espírito Santo
}

Resumo: A presente pesquisa apresenta um panorama da Psicologia Escolar em escolas públicas e privadas de Vitória. Foram entrevistados 34 sujeitos, todos de escolas diferentes, sendo quatro psicólogos e 30 outros profissionais de educação. Constatou-se que os poucos psicólogos atuantes não possuíam vínculo empregatício com as escolas e relatavam insatisfação com o trabalho. Os demais profissionais afirmaram que o psicólogo na escola deve trabalhar com os relacionamentos entre alunos, pais e professores. A maioria dos sujeitos considerou o trabalho do psicólogo na escola importante, ainda que, naquelas que não possuíam serviço de psicologia, outros profissionais acabavam por “fazer o papel” do psicólogo.

Palavras-chave: psicologia escolar; educação; aprendizagem; atuação profissional.

\section{PANORAMA OF THE EDUCATIONAL PSYCHOLOGY IN THE CITY OF VITORIA: AN EXPLORATORY STUDY}

\begin{abstract}
This research presents a panorama of the Educational Psychology services in public and private schools in Vitoria. Four psychologists and thirty other professionals that worked in different schools were interviewed. The psychologists that were working in the schools did not have official employee links. They frequently complained about the job they did in the schools. The majority answered that educational psychologists should work with the relationship between students, teachers and parents. They considered that it was important to have a psychologist in the school. Even in the schools that did not have a psychologist, others professionals often "play the role" of the psychologist.
\end{abstract}

Key-words: educational psychology; education; learning; professional practice.

Qual a real situação da Psicologia Escolar brasileira? Diversas pesquisas têm sido feitas em nosso meio para tentar responder esta questão. Segundo Andaló (1984) a Psicologia escolar tem sido tratada como área secundária da Psicologia, teoricamente não requerendo muito preparo nem experiência para ser exercida, sendo pouco valorizada ou dispensável nas escolas.

A revisão da literatura sobre o assunto tam-

\footnotetext{
${ }^{1}$ Artigo recebido para publicação em 22/08/2003; aceito em 03/11/2003. ${ }^{2}$ Endereço para correspondência: Claudia Broetto Rossetti, Departamento de Psicologia, Cemuni VI, Universidade Federal do Espírito Santo, Av. Fernando Ferrari, s/nº, Goiabeiras, Vitória, ES, Cep 29060-900, E-mail cbroetto@npd.ufes.br
}

bém mostra que muitos psicólogos que trabalham na área de Psicologia Escolar no país não se dedicam exclusivamente à área e têm visões predominantemente clínicas e estereotipadas das questões relacionadas às dificuldades de aprendizagem (Almeida, S.F.C., Rabelo, L. de M., Cabral, V. S., Moura, E. R. de O., Barreto, M. de S. F., 1995; Wechsler, 1989).

Trabalhos mais recentes apontam para o fato de que muitas das lacunas referentes à formação do psicólogo escolar no país resultam de fatores como inadequação curricular, falta de estágios bem supervisionados na área e despreparo acadêmico das agências formadoras (Novaes, 2001). 


\section{Claudia Broetto Rossetti}

De fato, vários autores ressaltam a necessidade de construção de modelos de atuação específicos para a realidade brasileira e também padrões éticos que assegurem a qualidade dos serviços prestados em Psicologia Escolar (Guzzo, 2001).

No caso do município de Vitória a realidade permanece pouco investigada. Os dados mais recentes foram apresentados pelo Conselho Regional de Psicologia - $4^{a}$. Região (2002), em uma pesquisa realizada para traçar o perfil dos Psicólogos atuantes no estado do Espírito Santo. De um total de 657 entrevistados (395 no município de Vitória), apenas 21\% declararam atuar na área de Psicologia Escolar.

Um fato que chama a atenção é que foi aprovada em dezembro de 2001 a Lei Estadual no. 6.974, que institui o Serviço de Psicologia Escolar na rede pública estadual de ensino fundamental e médio. Contudo, essa lei parece continuar pouco conhecida pelos profissionais da área de educação de uma maneira geral. De fato, até o presente momento, nenhum concurso público foi realizado em âmbito estadual para o cargo de Psicólogo Escolar.

Dessa maneira, a presente pesquisa teve como objetivo apresentar um panorama dos serviços de Psicologia Escolar em instituições de ensino públicas e privadas do município de Vitória, bem como as concepções que os demais profissionais de educação têm a respeito dessa área da Psicologia.

\section{Método}

\section{Participantes}

Segundo o último Censo (IBGE, 2000), o município de Vitória possui 111 estabelecimentos de ensino fundamental. Esta pesquisa contou com a participação de sujeitos de 34 destas escolas, sendo quatro psicólogos e 30 profissionais diversos da área de educação, notadamente Orientadores Educacionais, com formação em Pedagogia. Do total de sujeitos, 23 trabalhavam em escolas particulares (sendo três psicólogos) e 11 trabalhavam em escolas públicas (sendo apenas um psicólogo). Todos os sujeitos entrevistados eram do sexo feminino.

\section{Instrumentos e procedimentos}

Foram utilizados como instrumentos dois ro- teiros de entrevista distintos para os profissionais psicólogos e não-psicólogos. No caso dos psicólogos, o roteiro de entrevista constou de seis questões iniciais de identificação pessoal e mais 17 questões abertas, sobre a formação, a escolha da área de atuação, os pontos positivos e negativos da atuação, etc.

No caso dos não-psicólogos, foi utilizado um roteiro de entrevista simplificado, contendo cinco questões abertas com o objetivo de avaliar o conhecimento desses profissionais sobre o trabalho de um psicólogo escolar.

As entrevistas foram feitas no local de trabalho, individualmente, e parece importante ressaltar a dificuldade de agendar tais entrevistas. Muitas escolas, consultadas inicialmente por telefone, simplesmente alegaram motivos diversos para não permitir que seus profissionais participassem da pesquisa.

Em relação aos profissionais não-psicólogos, foram estabelecidas categorias a posteriori, nas quais as respostas encontradas nas entrevistas puderam ser enquadradas.

\section{Resultados e Discussão}

Tendo em vista o número extremamente reduzido de entrevistas realizadas com psicólogos (apenas quatro), apresentam-se detalhadamente apenas os resultados obtidos a partir das entrevistas realizadas com os profissionais não-psicólogos.

Contudo, de uma maneira geral, pode-se perceber que os psicólogos escolares entrevistados não possuíam vínculo empregatício formal com as escolas em que atuavam (prestavam assessoria, eram estagiários, etc.) e não estavam nas escolas durante todos os dias da semana. Este fato parece bastante relevante para a demarcação do lugar desses profissionais nestas instituições. No caso das escolas públicas, a inserção da psicologia escolar é praticamente inexistente.

As entrevistas com os psicólogos escolares consistiram, de uma maneira geral, de uma longa lista de reclamações em relação às dificuldades de atuação nessas instituições. Com relação ao referencial teórico, a maioria dos entrevistados afirmou não seguir um específico, mas observa-se a predominância de abordagens clínicas, o que corrobora os dados 
obtidos nas pesquisas feitas em âmbito nacional.

Com relação aos demais profissionais de educação entrevistados, quando perguntados sobre os motivos de não haver psicólogo em suas escolas, todos os sujeitos da rede pública deram respostas que apontam para a falta de decisão política de criar e priorizar tais cargos. Nenhum dos entrevistados fez referência à Lei Estadual no. 6.974 que institui e Serviço de Psicologia Escolar na rede de ensino estadual. No caso da rede particular, $40 \%$ dos entrevistados acham que não há necessidade do psicólogo na escola, enquanto que $25 \%$ apontam para a falta de recursos financeiros para criar e manter o cargo, como pode ser visto na Tabela 1:

Tabela 1: Respostas dos sujeitos quando perguntados sobre os motivos de não haver psicólogo em suas respectivas escolas.

\begin{tabular}{|c|c|c|}
\hline $\begin{array}{c}\text { Porque } \\
\text { não tem } \\
\text { psicólogo? }\end{array}$ & $\begin{array}{l}\text { Escolas } \\
\text { Públicas }\end{array}$ & $\begin{array}{c}\text { Escolas } \\
\text { Particulares }\end{array}$ \\
\hline Decisão política & $10(100 \%)$ & - \\
\hline Não há necessidade & 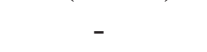 & $8(40 \%)$ \\
\hline Falta de recursos & - & $5(25 \%)$ \\
\hline $\begin{array}{l}\text { Já teve e não deu } \\
\text { certo }\end{array}$ & - & 3 (15\%) \\
\hline Trabalho feito por & & \\
\hline outro profissional & - & $3(15 \%)$ \\
\hline $\begin{array}{l}\text { Os pais não } \\
\text { aceitaram }\end{array}$ & $\begin{array}{lll}- & - \\
-1\end{array}$ & $1(5 \%)$ \\
\hline Total & $10(100 \%)$ & $20(100 \%)$ \\
\hline
\end{tabular}

Os sujeitos também foram perguntados sobre seu conhecimento ou não do trabalho do psicólogo escolar. Na rede pública, metade dos sujeitos afirmou conhecer a atuação do psicólogo na escola, enquanto na rede particular, $65 \%$ dos entrevistados afirmaram conhecer essa atuação.

Quando solicitados a falar sobre como imaginavam que poderia ser o trabalho do psicólogo na escola, $70 \%$ dos profissionais da rede pública deram respostas que tinham uma clara ênfase nos relacionamentos interpessoais, ou seja, o psicólogo escolar é visto como aquele que trabalhará as relações entre alunos, pais e professores. No caso das escolas parti- culares, o mesmo tipo de resposta, com ênfase nos relacionamentos interpessoais, foi dado por $55 \%$ dos entrevistados. De uma maneira geral, as respostas foram bastante semelhantes nos dois grupos, como pode ser observado na Tabela 2.

Tabela 2: Respostas dos sujeitos sobre como poderia ser o trabalho dos psicólogos as escolas.

\begin{tabular}{|l|c|c|}
\hline $\begin{array}{l}\text { Como seria o } \\
\text { trabalho do } \\
\text { psicólogo? }\end{array}$ & $\begin{array}{c}\text { Escolas } \\
\text { Públicas }\end{array}$ & $\begin{array}{c}\text { Escolas } \\
\text { Particulares }\end{array}$ \\
\hline $\begin{array}{l}\text { Ênfase nos } \\
\text { relacionamentos }\end{array}$ & $7(70 \%)$ & $11(55 \%)$ \\
$\begin{array}{l}\text { Ênfase nos } \\
\text { processos de } \\
\text { aprendizagem }\end{array}$ & $2(20 \%)$ & $7(35 \%)$ \\
$\begin{array}{l}\text { Ênfase no resgate } \\
\text { de valores }\end{array}$ & - & $1(5 \%)$ \\
$\begin{array}{l}\text { Ênfase na } \\
\text { disciplina }\end{array}$ & $1(10 \%)$ & - \\
$\begin{array}{l}\text { Ênfase na } \\
\text { prevenção } \\
\text { Total }\end{array}$ & - & $1(5 \%)$ \\
\hline
\end{tabular}

Perguntou-se também se os entrevistados achariam importante a presença de um profissional de psicologia nas escolas em que trabalham. Em ambos os grupos entrevistados a importância da presença do psicólogo na escola foi bastante ressaltada (80\% na rede pública e $75 \%$ na rede particular). Constatou-se, no entanto, que tais afirmações eram feitas em geral de maneira pouco enfática, ou seja, não foi possível detectar, na fala da maioria dos entrevistados, uma inclinação da instituição no sentido de tomar providências concretas para viabilizar a contratação de psicólogos.

Por último, perguntou-se aos entrevistados se alguém "faz o papel” de psicólogo na escola na qual eles trabalham. No caso da rede pública, metade dos entrevistados disse que ninguém ocupa esse lugar. No grupo da rede particular, apesar de 35\% dos entrevistados também afirmarem que ninguém ocupa esse lugar, outros $30 \%$ disseram que os orientadores educacionais acabam desempenhando esse papel. Respostas mais detalhadas sobre essa questão podem ser conferidas na Tabela 3. 
Tabela 3: Respostas dos sujeitos à pergunta: alguém "faz o trabalho" do psicólogo em suas escola?

\begin{tabular}{|l|c|c|}
\hline $\begin{array}{c}\text { Alguém “faz o } \\
\text { trabalho" do } \\
\text { psicólogo? }\end{array}$ & $\begin{array}{c}\text { Escolas } \\
\text { Públicas }\end{array}$ & $\begin{array}{c}\text { Escolas } \\
\text { Particulares }\end{array}$ \\
\hline Não & $5(50 \%)$ & $7(35 \%)$ \\
$\begin{array}{l}\text { Orientadora } \\
\text { educacional }\end{array}$ & - & $6(30 \%)$ \\
Diretora & - & $2(10 \%)$ \\
Professores & - & $2(10 \%)$ \\
Pedagogo & $3(30 \%)$ & - \\
Todo mundo & $1(10 \%)$ & $1(5 \%)$ \\
Psicopedagoga & - & $1(5 \%)$ \\
Conselheiro & - & $1(5 \%)$ \\
Supervisora & $1(10 \%)$ & - \\
Total & $\mathbf{1 0}(\mathbf{1 0 0} \%)$ & $\mathbf{2 0}(\mathbf{1 0 0} \%)$ \\
\hline
\end{tabular}

Dessa maneira, uma análise mais detalhada dos dados apresentados acima leva à conclusão de que, de fato, alguém acaba tratando das "questões psicológicas" que surgem no cotidiano das escolas, sobretudo nas escolas particulares, ainda que um profissional da área de Psicologia Escolar não esteja presente.

\section{Considerações Finais}

Os dados apresentados acima permitiram traçar um panorama consistente dos serviços de Psicologia Escolar em instituições de ensino públicas e privadas do município de Vitória, bem como das concepções que os demais profissionais de educação têm a respeito dessa área da Psicologia.

Em primeiro lugar, foi bastante surpreendente o escasso número de psicólogos atuando nas escolas pesquisadas. Esperava-se, de uma certa forma, que não houvesse psicólogos atuando na maioria das escolas, mas o número reduzidíssimo desses profissionais leva à constatação de que, na verdade, atualmente, o Serviço de Psicologia Escolar não se encontra inserido no cotidiano das instituições escolares do município de Vitória.

Esse panorama pode vir a mudar com o efetivo cumprimento da Lei Estadual no. 6.974, que ins- titui o serviço de Psicologia Escolar na rede pública estadual de ensino fundamental e médio do Estado, por meio da realização de concursos públicos para o cargo de Psicólogo Escolar e também por meio da efetiva entrada da Psicologia Escolar no âmbito das escolas privadas.

Em relação aos demais profissionais de educação entrevistados, pode-se constatar que, apesar de uma parcela significativa da amostra declarar que conhece o trabalho do psicólogo, esse conhecimento parece estar muito mais ligado a uma certa noção estereotipada e limitada da atuação de um profissional de psicologia em uma escola. De fato, grande parte das respostas da categoria "ênfase nos relacionamentos" aponta para atendimentos individuais e/ou clínicos, sobretudo no que diz respeito aos alunos.

Foi possível constatar também que a psicologia escolar, bem como os psicólogos que atuam na área, tendem ainda a ser vistos como "corpos estranhos” à rotina da escola. Profissionais misteriosos que ora são pensados como todo-poderosos capazes de resolver toda e qualquer questão em um passe de mágica, ora são vistos como incapazes e até nocivos (por questionarem demais, por exemplo) ao bom funcionamento da instituição escolar.

Dessa maneira, é possível verificar que o panorama da psicologia escolar na cidade de Vitória não é bom. A inserção de profissionais da área é muito pequena e as razões alegadas para tal fato apontam para um desconhecimento das contribuições possíveis da Psicologia Escolar para a Educação, que pode se dar no trabalho com toda a instituição escolar, na discussão e a reformulação dos processos de avaliação, na proposta de novas metodologias de ensino, na prevenção, avaliação e intervenção no que diz respeito às dificuldades de aprendizagem, entre muitas outras.

\section{Referências Bibliográficas}

Almeida, S.F.C. , Rabelo, L. de M., Cabral, V. S., Moura, E. R. de O., Barreto, M. de S. F. \& Barbosa, H. (1995). Concepções e práticas de psicólogos escolares acerca das dificuldades de aprendizagem. Psicologia: Teoria e Pesquisa, 11 (2), 117-134. 
Andaló, C.S. de A. (1984). O papel do psicólogo escolar. Psicologia, Ciência e Profissão. 4(1), 4346.

Conselho Regional de Psicologia - 4 ${ }^{\mathrm{a}}$ Região. Quem somos? Onde Estamos? O que fazemos? O perfil do Psicólogo no Estado do Espírito Santo. Vitória: 2002. [brochura].

Espírito Santo. Leis, etc. Lei no. 6.974 de 21 de Dezembro de 2001. Autoriza o Poder Executivo a instituir o Serviço de Psicologia Escolar na rede pública estadual de ensino fundamental e médio. Diário Oficial do Estado. Espírito Santo, 23 dez. 2001.

Guzzo. R.S.L. (2001). Formando psicólogos escolares no Brasil, dificuldades e perspectivas. Em S.M. Wechsler (org.), Psicologia escolar: pesquisa, formação e prática (pp. 75-92). Campinas: Editora Alínea.

Instituto Brasileiro de Geografia e Estatística (2000). Informação disponível na internet: http:// www.ibge.gov.br [09 out. 2003].

Novaes, M.H. (2001). Visão transdisciplinar na formação do psicólogo escolar. Em S. M. Wechsler (org.), Psicologia escolar: pesquisa, formação e prática (pp. 127-136). Campinas: Editora Alínea.

Wechsler, S.M. (1989). Panorama nacional da formação e atuação do psicólogo escolar. Psicologia: Ciência e Profissão. 9(3), 26-30.

Os autores agradecem aos alunos Alice Emília da Silveira, Anna Silvia Vassem, Bruno Pandolfi Coelho, Christianny Maria Brambila, Cristina Grasseli, Melissa Litwin Rocha e Patrícia Lopes Cordeiro pela participação na coleta dos dados que originaram o presente artigo. 